\title{
Characterisation of Weld Zone Reactions in Dissimilar Glass-to-Aluminium Pulsed Picosecond Laser Welds
}

DOI:

10.1016/j.matchar.2016.08.013

\section{Document Version}

Accepted author manuscript

Link to publication record in Manchester Research Explorer

\section{Citation for published version (APA):}

Ciuca, O., Carter, R., Prangnell, P., \& Hand, D. P. (2016). Characterisation of Weld Zone Reactions in Dissimilar Glass-to-Aluminium Pulsed Picosecond Laser Welds. Materials Characterization, 120, 53-62.

https://doi.org/10.1016/j.matchar.2016.08.013

\section{Published in:}

Materials Characterization

\section{Citing this paper}

Please note that where the full-text provided on Manchester Research Explorer is the Author Accepted Manuscript or Proof version this may differ from the final Published version. If citing, it is advised that you check and use the publisher's definitive version.

\section{General rights}

Copyright and moral rights for the publications made accessible in the Research Explorer are retained by the authors and/or other copyright owners and it is a condition of accessing publications that users recognise and abide by the legal requirements associated with these rights.

\section{Takedown policy}

If you believe that this document breaches copyright please refer to the University of Manchester's Takedown Procedures [http://man.ac.uk/04Y6Bo] or contact uml.scholarlycommunications@manchester.ac.uk providing relevant details, so we can investigate your claim.

\section{OPEN ACCESS}




\title{
Characterisation of Weld Zone Reactions in Dissimilar Glass-to-Aluminium Pulsed Picosecond Laser Welds
}

\author{
Octav P. Ciuca ${ }^{\mathrm{a}}$, Richard M. Carter ${ }^{\mathrm{b}}$, Philip B. Prangnell ${ }^{\mathrm{a}}$, and Duncan P. Hand ${ }^{\mathrm{b}}$ \\ ${ }^{a}$ School of Materials, University of Manchester, Manchester, M13 9PL, UK \\ ${ }^{b}$ Institute of Photonics and Quantum Sciences, Heriot-Watt University, Edinburgh, EH14 4AS, UK
}

\begin{abstract}
Precision welded joints, produced between fused silica glass and aluminium by a newlydeveloped picosecond-pulse laser technique, have been analysed for the first time using a full range of electron microscopy methods. The welds were produced as lap joints by focusing a 1.2 $\mu \mathrm{m}$ diameter laser beam through the transparent glass top sheet, slightly below the surface of the metal bottom sheet. Despite the extremely short interaction time, extensive reaction was observed in the weld zone, which involved the formation of nanocrystalline silicon and at least two transitional alumina phases, $\gamma-$ and $\delta-\mathrm{Al}_{2} \mathrm{O}_{3}$. The weld formation process was found to be complex and involved: the formation of a constrained plasma cavity at the joint interface, non-linear absorption in the glass, and the creation of multiple secondary keyholes in the metal substrate by beam scattering. The joint area was found to expand outside of the main interaction volume, as the energy absorbed into the low conductivity and higher melting point silica glass sheet melted the aluminium surface across a wider contact area. The reasons for the appearance of nanocrystalline $\mathrm{Si}$ and transitional alumina reaction products within the welds are discussed.
\end{abstract}

Keywords: Ultrashort pulse laser; Microwelds; Interface reaction layer; Transitional alumina phases; Microstructure; Electron microscopy

http://dx.doi.org/10.1016/j.matchar.2016.08.013

Corresponding author.

Tel: +44 (0) 161306 3552; E-mail address: octav.ciuca@manchester.ac.uk 


\section{Introduction}

The ability to join glasses to metals, or to silicon, is an increasingly relevant technology for applications that include the manufacture of optical sensors, actuators, and the hermetic wafer-level encapsulation of electronic components in the production of MEMS and 'lab-ona-chip' systems [1,2]. A range of processes are currently used for joining such very dissimilar materials, including; direct bonding [3,4], anodic bonding [1,5], glass frit joining [6], eutectic bonding or adhesive bonding [2,7]. Unfortunately, these techniques are often poorly suited for glass-to-metal micro-joining due to intrinsic limitations, such as: the need for heat treatments, which may damage temperature-sensitive components $[2,5,6]$, the development of residual stresses, resulting from the large difference in thermal expansion coefficients of the joined materials [2], and in-service issues that arise from polymer-based adhesives, like poor hermeticity [7], creep and outgassing.

In this context high pulse-rate laser microwelding is of growing interest, not only for avoiding the limitations imposed by the above techniques, but also because it offers the advantages of higher production rates and precise joint positioning. In addition, the extremely short thermal cycles induced by an ultrashort pulsed laser can in principle help prevent thermal damage and limit the formation of detrimental reaction products (e.g. intermetallic compounds, oxides, etc.) between dissimilar weld members at the joint interface [2].

With glass to glass welding it has been shown that successful microwelds can be produced using laser systems that deliver high-intensity, ultrashort (femto- or picosecond) laser pulses to the work piece [8-13]. This technique exploits the property of nonlinear optical absorption of the laser radiation in transparent materials, which allows the laser energy to be applied to a precise location within the workpiece volume in the vicinity of the beam focal point $[9,13]$. Thus, microweld lap joints can be achieved at the contact interface by focusing a pulsed laser beam through one of the glass sheets at the required depth. The resulting volume of molten 
glass generated, although small, is sufficient to fill the micron-scale gap between the glass sheets, which occurs by melt flow, driven by thermal expansion and the formation of a highly constrained plasma $[8,12]$. This micro-melt volume then solidifies to form the joint, and by translating the beam strong joints can be produced by controlling the net weld area (e.g. [8]).

Another major advantage of pulsed laser microwelding is that the heat-affected zone (HAZ) resulting from the microsecond-scale thermal cycles of a focused pulsed laser beam is much smaller than in the case of continuous fusion welding methods. The use of repeated short thermal cycles can also lead to significantly lower thermal stress levels between materials with very different thermal expansion coefficients and, thus, to welds less prone to cracking and premature failure $[5,8,9,14]$.

In a more recent development the feasibility of using a picosecond pulsed laser to join silica glass to various metal substrates has been demonstrated by the current authors [15]. In this work, the beam was transmitted through the glass sheet and focused into the metal surface, just below the joint interface. In all the weld samples produced by this method lap shear test pieces were found to fracture within the parent glass sheet, with the crack path travelling around the modified glass region, suggesting the welds had high interface bond strength. This is despite the fact that with certain glass-metal combinations there is a high thermodynamic driving force for chemical reaction to occur between the weld members. For example, when in contact with molten aluminium, under equilibrium conditions it is well known that $\mathrm{SiO}_{2}$ will be reduced to form alpha-alumina and silicon [16-18]. Although currently little is known about the interface structure in metal-glass micro-laser welded joints, under the highly transient conditions found in picosecond pulsed laser welding, this reaction may not have time to occur and alternative metastable products may form (e.g. [19-21]).

Here, we aim to address this knowledge gap by reporting on the results of a detailed microstructural study performed on the interface region of glass-to-metal microwelds 
produced using a solid-state, $1030 \mathrm{~nm}$, picosecond-pulsed laser with an average power of 2 $\mathrm{W}$, between fused silica glass and aluminium. Of particular interest was to understand the mechanisms of weld formation and the extent of chemical reaction that takes place at the joint interface, as well as to determine the effects of the microwelding conditions specific to rapid laser pulsing on the resulting interface microstructure. 


\section{Materials and Methods}

A set of glass-metal micro welds was produced at Heriot-Watt University using a Trumpf TruMicro 5 x 50 laser with a pulse duration of 5.9 ps at a repetition rate of $400 \mathrm{kHz}$. To produce the welds, a $1 \mathrm{~mm}$ thick sheet of commercial purity aluminium $(99.7 \% \mathrm{Al})$ was welded to a $1 \mathrm{~mm}$ thick sheet of fused silica glass with the spiral track pattern shown in Fig. 1(a). The fused silica glass grade chosen for this work was the ultra-high purity Spectrosil 2000 , due to its excellent optical transmission for the laser wavelength used in the present experiments $(1030 \mathrm{~nm})$. The aluminium sheet was first polished to a mirror finish and then clamped against the glass using a pneumatically-actuated, four-point loading-jig that brought the two surfaces into close contact. A small area of optical contact was thus created above the jig piston. The jig assembly was mounted on a stage with motorized controls in the $\mathrm{X}$ and $\mathrm{Y}$ directions.

The laser beam was transmitted normal to the surface through the glass top sheet and the beam was focused slightly $(\sim 100 \mu \mathrm{m})$ below the interface of the two materials in the area of optical contact. The laser had an average power of $2 \mathrm{~W}$ and a focused spot size of $1.2 \mu \mathrm{m}$. The stage-mounted assembly was translated at a speed of $1 \mathrm{~mm} \cdot \mathrm{s}^{-1}$ under a stationary laser beam along a spiral path with a pitch of $0.1 \mathrm{~mm}$ to produce a continuous weld seam, resulting in a circular welded area with a final diameter of $2.5 \mathrm{~mm}$ (Fig. 1(a)). Small deviations from an ideal spiral, visible in the seam in Fig. 1(a), are the result of backlash of the $x-y$ translation stage used. The microwelding procedure is described in full in [15]. To investigate the microstructure and phase distribution at the weld interface, representative weld areas were subsequently sectioned across their diameter to expose a cross-section through the weld seams (Fig. 1(b)). Metallographically prepared cross-sections were then investigated in an ultra-high resolution FEI Magellan 400 field-emission-gun scanning electron microscope (FEG-SEM) using backscattered electron (BSE) imaging at an accelerating voltage of $3 \mathrm{kV}$, 
and energy-dispersive $\mathrm{X}$-ray spectroscopy (EDS) at $5 \mathrm{kV}$, in order to determine the morphology and phase composition of the weld regions. Small, site-specific samples were also extracted from the cross-sections of the welded interfaces and thinned to electron transparency using focused ion beam (FIB) milling, for analysis by transmission electron microscopy (TEM). The TEM samples were studied in an FEI Tecnai T20 microscope, in standard imaging and diffraction modes, and in STEM mode to obtain Z contrast by annular dark field (ADF) imaging and for elemental mapping by EDS. 


\section{Results}

\subsection{Weld zones}

A surface overview of the welded area produced by translating the beam through the spiral pattern used in this study and a low magnification cross-section through three tracks is shown in Fig. 1. An SEM backscattered electron (BSE) image of a typical individual weld track is also provided in cross section in Fig. 2, along with a corresponding overlaid SEM-EDS elemental map, showing the coarse-scale distribution of the main elements (i.e. $\mathrm{Si}, \mathrm{O}$ and $\mathrm{Al}$ ) present in the two weld members. To aid interpretation, the main microstructurally distinct weld features described below have been labelled in Fig. 2(a). Further individual higher magnification elemental maps of the main central weld area are also provided in Fig. 3 along with a BSE image.

Overall, a complex chemically heterogeneous microstructure can be seen, containing cavities, porosity and microcracks, which is indicative of a highly energetic material-beam interaction and non-equilibrium reaction process. In Figs. 1 to 3 a significant amount of fine porosity, as well as coarse cavities, can be seen associated with each weld track. Caution is required in terms of interpreting the size and volume fraction of the cavities in the glass side of the weld, because the preparation of such a brittle sample by metallography is extremely difficult, without inadvertently removing some fragments from the porous weld regions. Nevertheless, in Fig. 2(a) it can be seen that at the laser beam position there is a main central weld zone, consisting of an approximately $20 \mu \mathrm{m}$ wide semi-circular modified region in the glass top sheet. The images suggest that in the vicinity of the beam focus position there was a main plasma cavity in the glass top sheet that has subsequently partially collapsed, but there is also a secondary neighbouring cavity in the glass, in close proximity (to the right in Fig. 2 (a)). Directly below the beam position and the main cavity there is clear evidence of a $5.5 \mu \mathrm{m}$ deep 
keyhole being formed in the aluminium bottom sheet. In comparison, the keyhole in the aluminium surface under the secondary cavity in the glass is less deep. There are also additional smaller keyholes in the aluminium sheet further away from the beam focus position, in locations where the laser beam would not have had sufficient energy to cause a plasma cavity to form in the glass. Across this entire area, and extending to a further width than the secondary smaller keyholes, there is a thin interface layer consisting of Al oxide, where chemical interaction with the glass has occurred (Fig. 2(b)) (see Discussion below). This thin interface interaction area extends sideways a considerable distance of around $16 \mu \mathrm{m}$ either side of the main weld zone. Thus, despite the application of a highly focused laser with a spot size of approximately $1.2 \mu \mathrm{m}$, for each weld track, the entire area over which a chemical bond had formed was about $50 \mu \mathrm{m}$ wide, which would be expected to have considerably increased the mechanical strength of the joint [22].

A thin band of regularly spaced microcracks (Figs. 2(a) and 3) was also found across the entire laser affected area, where chemical interaction had occurred between the two weld members at the interface between the reacted layer and the glass sheet (i.e. across both the main weld zone where the beam was focused and the thinner surrounding interface reaction layer). These cracks were approximately $0.6 \mu \mathrm{m}$ long and had a spacing periodicity of about $0.4 \sim 0.6 \mu \mathrm{m}$.

The extent of possible melting of the glass and aluminium substrates during the welding process was very difficult to determine, as there are no microstructural markers present in the glass, and few in the commercial purity $\mathrm{Al}$ alloy. The grain structure of the Al substrate near the fusion region, readily seen in an ion-beam polished section through a neighbouring weld bead (Fig. 4), shows no clear evidence of changes caused by a significant melt depth. In addition, Fe-rich (typically $\alpha$-AlFeSi and $\mathrm{Al}_{3} \mathrm{Fe}$ ) inclusions visible within the $\mathrm{Al}$ sheet equally 
appear not to be altered very close to the $\mathrm{Al}$ sheet surface. Overall this suggests any $\mathrm{Al}$-rich liquid layer generated at the Al sheet surface during welding was very localised, being probably of the order of less than $200 \mathrm{~nm}$ thick.

Sub-micron scale chemical heterogeneity within the weld zones cannot be reliably measured by EDS in an SEM due to the limited spatial resolution $(0.1 \sim 0.2 \mu \mathrm{m}[23])$ inherent with this technique, even when using the low accelerating voltage with which this analysis was conducted. This precluded accurate quantitative determination of the compositions of any individual phases by SEM. It should also be noted that some of the oxygen and silicon detected in the pores, as well as in the larger cavities, resulted from the presence of trapped colloidal $\mathrm{SiO}_{2}$ particles that originated from the oxide suspension used in the final step of sample polishing. This contamination was difficult to remove through cleaning, due to the fragile nature of the samples. However, the SEM-EDS maps in Fig. 2 are still helpful in providing a qualitative assessment of the coarse-scale distribution of the main elements present within a typical weld.

It can be seen from Fig. 2(b), and the elemental maps in Fig. 3(b), that a high silicon content region with an average composition in the range 60 - 70 at.\% made up about $30 \%$ of the volume fraction of the main, central, weld zone. This Si-rich zone, marked in blue and labelled accordingly in Fig 2(a), appeared in the upper part (as depicted) of the main laser interaction volume in the glass side of the joint, with a distinct ' $W$ '-shaped distribution (see Fig. 3(b)). In the same area both the oxygen and Al maps (Figs. 3 (c) and (d)) showed correspondingly depleted concentrations and this, therefore, suggests that $\mathrm{Si}$ was present in a significant region of the weld as a separate phase, rather than as an oxide, or an Al-Si-O compound. This Si-rich region appeared to be associated with the main plasma cavity and also contained a high volume fraction of micro-porosity. 
Several more intense Si-rich concentration spots can be seen near the top of the EDS map on Fig. 3(b) (arrow i.), near the glass side of the weld in this Si-rich region, which also match positions from brighter areas in the BSE image in Fig 3(a), indicating the presence of some larger nano-scale crystalline $\mathrm{Si}$ particles within a region of very fine particles. This interpretation will be confirmed below by TEM analysis. In addition, a thin Si rich band could be seen near the Al substrate side of the weld (Fig. 3(b) arrow ii.).

In contrast to the $\mathrm{Si}$ distribution seen within the central main weld zone, the regions rich in $\mathrm{Al}$ in the EDS maps correlated well with the distribution of oxygen (Fig. 2(b), and Fig. 3(c) and (d)). A large Al-O rich region was found in the bottom half of the semi-circular weld zone in the glass sheet, nearer to the Al side of the joint, and this is also marked in Fig. 2(a). Based on these results, it can thus be expected that $\mathrm{Al}$ was present in the central region of the welds in the form of one, or more, oxide phases.

In the main weld zone a thin layer containing oxygen and rich in $\mathrm{Al}$ (arrow i. in Fig. 3(d)), with a lower content than that of the Al substrate, was also seen at the top of the weld immediately at the glass interface. In addition, a thin layer similarly rich in $\mathrm{Al}$ and $\mathrm{O}$ was identified along the entire thin interface reaction layer found either side of the main weld region in the elemental map overlay shown in Fig 2(b), where it appears as a yellow interface band, corresponding to an Al-O rich composition. While the presence of oxygen in such thin interface layers was not easy to distinguish, due to their close proximity to the parent glass, EDS analysis confirmed the presence of a strong oxygen signal in the same location, suggesting that these regions also contained an $\mathrm{Al}$ oxide phase.

Similar to in the Si region, within the central weld zone, high intensity EDS peaks were visible from discrete sub-micron areas in the Al distribution map (arrow ii. in 3(d)). These particles were also found to be O-rich, again indicating the presence of $\mathrm{Al}$ oxide. These larger Al-O particles were found to be located both at the interface near the thin Al-O rich layer, at 
the top of the weld zone, and dispersed in the 'W' shaped Si-rich region. However, although a few Al-O particles were dispersed in Si-rich regions, the boundaries between the Si-rich and the Al-O rich areas were generally sharply defined, indicating that there was very restricted inter-diffusion, or intermixing, between the two regions.

Finally, Fig. 5 shows an SEM-EDS line scan along the direction of the laser beam, but slightly off the centre line of the weld in Fig. 3(a), indicating the composition of the Si rich area and both the Al-O rich regions within the main fusion zone and the neighbouring thin reacted interface layer. It can be noted that the quantitative values do not indicate the presence of single phases in most of the weld volume, but rather a mixture of phases, due to both the limited spatial resolution of the technique - as discussed above - and the high level of heterogeneity along the weld path (in a direction normal to the cross-section). Nevertheless, the $\mathrm{Al}: \mathrm{O}$ atomic ratio gave a value close to $2: 3$ in the $\mathrm{Al}-\mathrm{O}$ rich areas, with maxima of $40 \%$ and $60 \%$ respectively for $\mathrm{Al}$ and $\mathrm{O}$, which matches the stoichiometry of alumina, $\mathrm{Al}_{2} \mathrm{O}_{3}$. $\mathrm{A}$ strong Si peak, reaching up to about $70 \%$, was also seen in the Si-rich area close to the glass interface, with a concurrent drop in the levels of both $\mathrm{Al}$ and $\mathrm{O}$ detected. Another, smallerintensity Si peak was also identified near the Al plate interface, matching the position of the bright-contrast layer in the BSE image and supporting the observation of the formation of a very thin layer of Si along the $\mathrm{Al}$ interface, noted above.

\subsection{Higher Resolution Phase Identification}

In addition to SEM analysis, TEM and STEM were used to identify the phases formed during the complex reaction process identified above and also to analyse the weld zone microstructures at higher resolution. Electron transparent rectangular samples (approximately $20 \times 11 \mu \mathrm{m}$ in size) were FIB-milled parallel to the laser beam scan direction and extracted for examination. Data obtained from a FIB sample from the weld centre line are shown in Fig. 6. 
A high level of chemical and microstructural heterogeneity was again found in this section view. In the STEM image and composition maps it can be seen that this region, which encompasses the main plasma cavity, appeared to consist largely of a Si-rich nano-crystalline phase, with several Al-O rich particles distributed within the Si rich matrix. The composition of the Si phase appeared to be nearly pure $\mathrm{Si}$, based on STEM analysis of the elemental distribution in the larger $\mathrm{Si}$-rich particles. Al-O rich regions were again seen at the interface between both the glass and the aluminium substrate, in agreement with the elemental distributions observed in the SEM weld cross-section views in Fig. 3. However, the Al-O rich layer near the Al substrate (lower half of Fig. 6 (b)) appeared to be thicker than the Al-O rich layer at the glass interface. The STEM-EDS maps showing the elemental distribution of oxygen in Fig. 6(c) can be seen to clearly match that for Al (Fig. 6(b)), confirming that Alrich areas present in the weld reaction zone were present as an oxide. STEM-EDS analysis gave an $\mathrm{Al}: \mathrm{O}$ ratio of $63.5: 36.5$, in good agreement with the SEM-EDS results. However, the thicknesses of these Al-O rich layers varied considerably along the welding direction. No region in the weld zone appeared to show the presence of mixed Al-Si-O compounds, with $\mathrm{Al}$ and Si having clearly separate distributions.

TEM imaging and selected area diffraction (SAD) analysis of the Si-rich regions seen across the centre of the weld reaction zone revealed it to be mostly comprised of nanocrystalline silicon, with crystallite sizes of $<40 \mathrm{~nm}$. This highly porous structure, seen in the central region of Fig. 6(a), is shown at a higher magnification in Fig. 7(a) and, in more detail, in (b). The small circular area selected (using a $\phi 750 \mathrm{~nm}$ aperture), indicated by the dashed circle in Fig. 7(a), produced the SAD pattern shown as an inset in Fig. 7(b). The almost-continuous Debye rings seen in this pattern indicate the presence of a large number of nano-crystallites of random orientation, present within the small volume sampled, confirming the extremely fine particle size visible in the bright-field image. The rings in the pattern were readily indexed as 
$f c c \mathrm{Si}$. This porous nanocrystalline $\mathrm{Si}$ microstructure extended across the entire ' $\mathrm{W}$ ' shaped central weld region that had been identified to be high in Si by SEM-EDS analysis in Fig. 3 and by TEM in Fig. 6(b). However it should also be noted this region contained some nanocrystalline Al-O rich particles and a small number of coarser ( $200 \mathrm{~nm}$ across $)$ discrete Si particles, consistent with the high Si intensity peaks found in the SEM-EDS maps (Fig. 3 (b)).

The microstructures of the Al-O rich zones found near to the glass and metal substrates in the welds were similarly investigated. A TEM image of the Al oxide region marked by the yellow box (i) in Fig. 6(a), in the vicinity of the Al substrate, is provided in Fig. 8. It reveals that this oxide layer is fragmented by roughly parallel periodic cracks. These features were consistent with the regular cracks previously shown in the SEM cross-sections in Figs. 2 and 3 (a), but when seen in the TEM had a slightly finer spacing of $0.25 \mu \mathrm{m}$. This micro-cracked Al-O rich region consisted of crystallographic domains of less than $0.5 \mu \mathrm{m}$ in width, with a small misorientation between them. Identification of the aluminium oxide phase proved more challenging than for $\mathrm{Si}$, as selected area diffraction data was not found to match the symmetry of the trigonal structure of the common stable form of $\alpha$-alumina (corundum). An extensive number of micro-diffraction patterns, corresponding to several distinct diffraction zones, were collected from discrete particles - one example of which is shown in Fig. 8(b). When considered together, this diffraction data was consistent with the presence of at least two metastable forms of alumina, namely the spinel-type, superlattice, $\gamma$ - and $\delta$-alumina phases described in refs. [24,25]. Either one, or both, of these phases were found as possible indexing solutions for the diffraction patterns obtained from crystals investigated in the Al oxide-rich weld regions, and one example match - for the [233] zone of the $\gamma$-phase - is given in Fig. 8(b). Distinguishing between these two phases is difficult, owing to indexing ambiguity that originates from their closely-related structures. In comparison, diffraction patterns produced 
by the larger discrete particles present in the weld region near the glass interface were more readily indexed as being consistent with the structure of $\delta$-alumina (see Fig. 9(a) - detailed view of the region marked by box (ii) in Fig. 6(a)) although in this case the exclusive presence of only one transitional alumina phase could not be unequivocally established.

The structure of the thin interface reaction layer formed away from the central weld region was also investigated by TEM, using FIB samples extracted from just outside the main laser interaction volume (as indicated by dashed line in Fig. 10(a)). Fig. 10(b) shows the typical aspect of this layer, which is approximately $650 \mathrm{~nm}$ thick, and reveals fine, periodic cracks similar to those seen in the interface layers in the main weld region. The chemical distribution maps of the area marked by the white dashed rectangle (Figs. 10(c) and (d)) show a thicker Al-O layer near the fused silica glass and a thinner Si-rich layer near the Al surface, both with similar chemistry to that found at the interfaces with the weld members in the main laser interaction volume. Compositional analysis across this interface layer revealed an average $\mathrm{Al}: \mathrm{O}$ atomic ratio of 40:60 in the $\mathrm{Al}-\mathrm{O}$ rich region, and a sharp spike in the Si-rich layer with a concurrent drop in concentration for all other elements. Overall, the interface reaction layer was identified by electron diffraction to contain a significant volume fraction of amorphous material, along with ultrafine dispersed crystallites (a characteristic diffraction pattern, acquired from the area marked by the white dotted circle within the interface layer, is shown as an inset in Fig. 10(b). Moreover, the possible presence of amorphous phase in the main laser interaction volume, while difficult to confirm, cannot be entirely dismissed.

The ultrafine crystalline fragments in the Al-O rich reaction layer shown in Fig. 10(b) are presented in more detail in Fig. 11. A CBED pattern produced by the fragment indicated by the white arrow - lower right inset - was indexed to match the [112] zone of the transitional $\gamma-\mathrm{Al}_{2} \mathrm{O}_{3}$ phase. Because of their similar symmetries, however, it is not possible to discount the presence of other transitional alumina phases in these fine fragments as well. 


\section{Discussion}

The results presented reveal a complex process of weld formation caused by the rapid application of many overlapping, picosecond, high energy-density laser pulses to a reactive glass-aluminium couple. It is very evident that where heating and contact occurred between these two materials, the silica phase has been reduced by reaction with the aluminium substrate. This took place under the highly transient conditions within the main laser interaction volume, which resulted in the formation of a metastable form of alumina and nano-crystalline silicon. However, multiple secondary keyholes were also formed in the Alsheet, and interfacial reaction was seen well outside the main laser interaction volume, which led to chemical bonding between the two weld members over a much larger area and was, thus, an integral part of the joint formation process. Welding also resulted in fine scale microcracking in the thin interface alumina layer across the entire joint area. This micro-cracking would be expected to be caused by a build up in internal stresses, generated by the $\sim 37 \%$ decrease in material volume [16] that is known to occur during chemical reaction between glass and aluminium and differences in thermal expansion and conductivity between the two weld members.

\subsection{Ultrashort pulse laser welding}

For the laser welding parameters used in the current study (beam focus $\phi \sim 1.2 \mu \mathrm{m}$, pulse frequency of $400 \mathrm{kHz}$ and a welding speed of $1 \mathrm{~mm} \mathrm{~s}^{-1}$ ) a simple calculation indicates that each point along the weld trajectory was exposed to up to 480 pulses, as it moved under the beam, with a total interaction time of just $1.2 \mathrm{~ms}$. Under such conditions, where a high frequency ultrashort-pulse laser has been used to weld silica glass to a reactive metal substrate with the applied energy focused through the transparent glass top sheet, weld formation involves the combined effects of several complex phenomena that include: i) heating of the metal substrate by linear absorption $[22,26]$; ii) rapid heating of the glass through nonlinear 
absorption $[8,13]$; iii) conduction between the glass and metal weld members; iv) plasma formation $[14,27]$; v) chemical reactions in the melted volume and also between the ionized species in the constrained plasma phase; and vi) rapid condensation of the plasma and solidification, involving the formation of new solid phases at the weld interface $[19,28]$.

It is evident from the images in Figs. 2 and 3 that in the area of direct focus of the laser beam a primary keyhole was produced in the $\mathrm{Al}$ bottom sheet and a plasma cavity also existed in the glass, which must have directly absorbed enough energy to locally melt the surrounding glass. A smaller, secondary plasma cavity was also seen close to this position. This central high energy density interaction volume resulted in the formation of the porous region seen in the glass sheet above the beam focus position, and which contained only reaction products. Other, smaller keyholes were also seen, both close to the horizontal focus position of the laser beam and further away from it, in the $\mathrm{Al}$ sheet. These secondary keyholes were produced as the incident laser beam was refracted, scattered and partly reflected by the plasma plume (an effect referred to as plasma shielding [27]) and the glass and aluminium sheet surfaces. While the formation of these keyholes is a consequence of using a high-intensity pulsed laser beam, investigations revealed that this level of intensity was required to reliably produce strong welds. Moreover, these microstructural defects did not cause detrimental effects to the mechanical behaviour of the welds, as no direct connection could be found between the presence of the keyholes and the initiation of cracks leading to failure, and the cracks typically propagated through the glass sheet around the modified glass region and away from the interaction volume.

In contrast to nonlinear optical absorption that causes localised heating in transparent materials, an opaque metallic material linearly absorbs the laser energy that is not reflected. In the case of a polished aluminium surface, absorptivity is initially poor until a plasma is formed, and for the $1030 \mathrm{~nm}$ wavelength laser used the absorptivity level would be expected 
to be of the order of $20 \%$ [29]. In the laser ablation of metals with similar ultrashort (femto and picosecond) pulses, a plasma is rapidly created through a process described by the "twotemperature model' $[27,28,30,31]$ in which the electrons in a thin surface layer absorb the pulse energy through multi-photon absorption. Due to the high energy intensity the electron cloud temperature reaches several thousand $\mathrm{K}$ within femtoseconds, while the ionic lattice remains relatively cold. It takes between 1 and 10 ps for thermal equilibrium to be reached in the lattice [28]. At these timescales, heat cannot diffuse further than a few nm into the bulk. Instead, a thin layer of ionized material is rapidly brought to a state of superheated liquid and is explosively evaporated $[27,31,32]$. This creates a high-temperature mixture of ionized gas, micron-sized particles and droplets. Normally, individual picosecond pulses are not sufficient to cause melting, due to dispersal of the high-temperature ablated plume and the high thermal conductivity of the metal substrate. However, when successive pulses are repeated with a sufficiently-high frequency - typically, anything above $125 \sim 200 \mathrm{kHz}$ - the heat generated by one pulse will not diffuse away completely before the next pulse arrives, and begins to accumulate in the substrate. A thin Al surface melt layer may therefore form across the region of optical absorption [26,31], but this would not explain the wider thin reaction layer noted above that occurred outside of the area of the main laser interaction volume.

In the specific case of fused silica-to-Al lap welds the plasma plume is also highly constrained by the surrounding glass. This causes all its thermal energy to be trapped locally, and as a result the glass it is in contact with heats up locally. This, in turn, would result in phononassisted optical absorption of the incoming pulses, and it is expected that the high pulse repetition rate used to produce the weld contributes to melting and plasma formation in the glass sheet. By this proposed mechanism, each successive pulse is absorbed partly in the $\mathrm{Al}$ plate (at least the first part of the pulse) and partly in the glass plate, and triggers the formation of a small plasma pool at the interface between the two materials, with melting 
predominantly occurring in the glass. This plasma pool is expected to reach a steady size as welding progresses, with the size being determined by factors such as the pulse power, the pulse repetition rate and the travel speed, as well as the material-characteristic physical properties (see below). This was significantly larger than that of the focused laser beam and can be equated here, in the particular case of dissimilar materials welding, to the size of the easily-identifiable interaction volume seen in the post-mortem investigations. In addition, owing to the poor thermal conductivity of fused silica, over two orders of magnitude lower than that of cp-Al $(1.4 \mathrm{~W} / \mathrm{m} . \mathrm{K}$, as opposed to $220 \mathrm{~W} / \mathrm{m} . \mathrm{K})$, the heated glass retains the thermal energy far more than the metal substrate, and thus heat will build up in the glass surrounding the plasma cavity/interaction volume. As the fused silica glass used in this study has a softening temperature of $1983 \mathrm{~K}\left(1710^{\circ} \mathrm{C}\right)$, which is over two times higher than the melting point of $\mathrm{cp}-\mathrm{Al}\left(933 \mathrm{~K}\left(1220^{\circ} \mathrm{C}\right)\right)$, the increase in temperature in the surrounding glass will therefore be sufficient to melt the surface of the contacting Al sheet by conduction. This mechanism of $\mathrm{Al}$ surface liquation, by conduction from the hot glass, is thus responsible for the observed spread of a thin alumina and Si-rich interface reaction layer across the joint interface, much further out than the main laser interaction volume.

\subsection{Weld zone reactions}

As joining of glasses to metals is a new development in the field of ultrafast pulsed-laser welding, to the authors' knowledge to date no comparable studies on phase formation within the weld zone have been published. Solid-state reaction would not be expected owing to the very short weld duration [9,31]. However, from the above discussion, it is apparent that reaction between the two weld members can occur both via the ionised species present in the plasma cavity and in the liquid phase, within the main weld zone, and further out where the Al sheet surface melted locally under the contact area with the hot (or possibly molten) fused silica. 
Pulsed laser ablation (PLA) of solid targets using ultrafast pulses has been extensively researched over the past few decades, as a technique for depositing thin films onto substrates. If PLA is carried out with reactive species present in the plasma it is commonly found that they form similar scale nanoparticles to those observed [28,33]. The application of a high frequency pulsed laser in dissimilar welding is, however, significantly different as it will be strongly affected by the physical confinement of the plasma. In this respect, Pulsed Laser Ablation of solid targets within a Liquid (PLAL) may be considered as a more closely comparable process. In contrast to atmospheric pressure ablation, PLAL leads to higher temperatures and pressures due to the confining effect of the liquid on the plasma, as well as much faster quenching. This allows the fabrication of nanocrystalline and far-fromequilibrium metastable phases by selecting the appropriate combination of target materials and laser parameters [19]. For example, in a publication relevant to the present work, PLAL of an $\mathrm{Al}_{2} \mathrm{O}_{3}$ target in water has been reported to produce $\gamma-\mathrm{Al}_{2} \mathrm{O}_{3}$ nanoparticles [21]. The very fine nano-scale $\mathrm{Si}$ and $0.5 \mu \mathrm{m}$ metastable alumina particles found in the highly porous weld zone in the glass sheet are therefore indicative of a reaction occurring under similar conditions. However, in the peripheral regions of the weld a reaction is more likely to have occurred in the liquid (molten $\mathrm{Al}$ ) phase.

Under equilibrium conditions $[16,17], \mathrm{Al}$ is known to reduce quartz via the reaction:

$$
3 \mathrm{SiO}_{2}+4 \mathrm{Al} \rightarrow 3 \mathrm{Si}+2 \mathrm{Al}_{2} \mathrm{O}_{3}
$$

where the thermodynamically stable form of alumina is $\alpha-\mathrm{Al}_{2} \mathrm{O}_{3}$ (corundum). This phase is based on a hexagonal close-packed $(h c p)$ anion stacking sequence, or sublattice, with $2 / 3^{\text {rds }}$ occupancy of the octahedrally coordinated interstitial sites by Al. In contrast, in the present study, only metastable forms of alumina, $\gamma$ and $\delta-\mathrm{Al}_{2} \mathrm{O}_{3}$, as well as an amorphous phase, were found within the welds. While this is the first report of transitional alumina phases being 
formed in a pulsed laser weld, several other closely related metastable phases, as well as amorphous $\mathrm{Al}_{2} \mathrm{O}_{3}$, have been previously observed on rapid quenching liquid $\mathrm{Al}_{2} \mathrm{O}_{3}$ or an $\mathrm{Al}-\mathrm{O}$ containing plasma $[34,35]$. For example, $\gamma-\mathrm{Al}_{2} \mathrm{O}_{3}$ has also been found to form as fine nanoparticles during the PLAL of $\alpha-\mathrm{Al}_{2} \mathrm{O}_{3}$ in water [20,21], and in similar research involving PLAL of an $\mathrm{Al}$ target in water, unidentified diffraction peaks suggested the synthesis of other transitional phases [36]. In work by Levi et al. $\mathrm{Al}_{2} \mathrm{O}_{3}$ particles, with sizes ranging between 10 $\mathrm{nm}$ and $300 \mu \mathrm{m}$, were produced by atomization from a melt [34], which varied from amorphous to $\gamma, \delta, \theta$ and $\alpha$ in order of increasing particle size and, correspondingly, reducing supercooling levels. A similar transition phase sequence has also been found when $\mathrm{Al}_{2} \mathrm{O}_{3}$ is plasma-sprayed on to a cold steel substrate [35].

In contrast to $\alpha-\mathrm{Al}_{2} \mathrm{O}_{3}$, the $\gamma, \eta, \delta$, and $\theta$ transitional phases all adopt a common, face-centred cubic $(f c c)$ structure for the $\mathrm{O}$ anions, with the Al cations taking up either tetrahedrally, or octahedrally, coordinated interstitial sites, the only difference between this series of phases being the specific arrangement of cations in the anion interstices [34,37]. Upon heating, transformation between the phases can occur displacively, as a result of ordering of the cation sublattice, following the $\gamma$ to $\theta$ sequence listed above [24]. Therefore, transformation to $\alpha$, from any of the $f c c$-based polymorphic structures, requires the reconstruction of the anion stacking sequence to $h c p[24,37]$.

Interestingly, the nearest-neighbour distances for $\mathrm{Al}-\mathrm{O}$ and $\mathrm{O}-\mathrm{O}$ in high-temperature $\mathrm{Al}$ oxide melts, and in supercooled liquids, have been found by X-ray synchrotron measurements to be more consistent with the tetragonal coordination of the $\mathrm{Al}$ cations found in the $f c c$-based transitional phases, rather than with the octahedral coordination in $\alpha-\mathrm{Al}_{2} \mathrm{O}_{3}$ [38]. This suggests that under rapid cooling conditions the nucleation of a transitional $f c c$ based polymorphic structure is favourable, as nucleation of $\alpha$ would necessitate a complete 
reconstruction of the tetrahedral $\mathrm{AlO}_{4}{ }^{5-}$ structural units in the liquid. Moreover, through studying nano-powders it has been shown that surface energy differences are sufficient to thermodynamically stabilise the $f c c$ transitional phases over $\alpha-\mathrm{Al}_{2} \mathrm{O}_{3}$ at particle diameters of $<$ $17 \mathrm{~nm}$ [39]. Calculations of the nucleation kinetics [34] also suggest that the transitional phase $\gamma$ should preferentially nucleate first, directly from rapidly quenched melts, while the other phases will subsequently form from $\gamma$ through solid-state transformation. In the present study, in which both the defect spinel structure $\gamma$-phase and the higher-symmetry $\delta$-phase were observed, it is reasonable to similarly conclude that $\alpha-\mathrm{Al}_{2} \mathrm{O}_{3}$ has been replaced by an fcc-based transitional phase that can nucleate more easily from molten alumina, or the vapour plasma phase, under rapid cooling conditions. It is also possible, in the post-mortem studies performed here, that only amorphous $\mathrm{Al}_{2} \mathrm{O}_{3}$ and $\gamma$ formed initially, and re-heating from subsequent laser pulses triggered transformation to $\delta$, by partially following the sequence noted above. 


\section{Conclusions}

The microstructure and interface reaction behaviour in dissimilar microwelded lap joints, produced between a silica glass sheet and an aluminium substrate, have been analysed for the first time by a range of electron microscopy methods. It has been found that the process of weld formation, that results from the rapid application of many overlapping picosecond highenergy-density, laser pulses, is a complex one, owing to its highly transient nature and the very different thermo-physical properties of the two weld members. Weld formation involved the formation of a constrained plasma cavity at the joint interface, rapid heating by non-linear absorption in the glass, and the creation of multiple secondary keyholes in the metal substrate by beam scattering. The joint area was also found to be expanded by the energy absorbed into the low conductivity, higher melting point silica glass sheet, which locally melts the aluminium substrate surface over a wider area of interface contact outside of the main laser interaction volume.

Despite the extremely short interaction time, extensive reaction was observed in the weld zone, which involved the formation of nanocrystalline silicon and transitional alumina phases. Reduction of the silica glass was also observed across a thin interface layer outside of the main interaction volume, where surface melting had occurred, leading to the formation of amorphous alumina containing disperse ultrafine crystallites of $\gamma-\mathrm{Al}_{2} \mathrm{O}_{3}$, and a thin Si layer.

The appearance of nanocrystalline $\mathrm{Si}$ and $\mathrm{Al}_{2} \mathrm{O}_{3}$ within the welds can be rationalised in terms of the high thermodynamic driving force for $\mathrm{Al}$ to reduce $\mathrm{SiO}_{2}$, and the potential for reaction of ionised species within the plasma cavity and the subsequent rapid quenching that occurs from both the plasma and liquid states, owing to the small weld zone and highly conductive Al substrate. Only transitional alumina phases, specifically $\gamma$ - and $\delta-\mathrm{Al}_{2} \mathrm{O}_{3}$, were confirmed to form in the weld zone. This is the first time such phases have been reported in a laser weld 
and are part of a family of metastable forms of $\mathrm{Al}_{2} \mathrm{O}_{3}$, based on a face-centred cubic $(f c c)$ structure for the $\mathrm{O}$ anion sublattice. It is suggested that these phases formed preferentially to the equilibrium, $h c p$-based anion structure of alumina (corundum $\alpha-\mathrm{Al}_{2} \mathrm{O}_{3}$ ), owing to their more favourable nucleation kinetics at high supercoolings.

\section{Acknowledgements}

The authors acknowledge support from the EPSRC Centre for Innovative Manufacturing in Laser-based Production Processes (EP/K030884/1), the Light Alloys Towards Environmentally Sustainable Transport (LATEST2) program (EP/G022402/1), and the Scottish Manufacturing Institute (EP/F02553X/1), as well as industrial partners Renishaw plc. and Selex ES. 


\section{References}

[1] Y. Temiz, R.D. Lovchik, G.V. Kaigala, E. Delamarche, Lab-on-a-chip devices: How to close and plug the lab?, Microelectron. Eng. 132 (2015) 156-175. doi:10.1016/j.mee.2014.10.013.

[2] K.F. Tamrin, Y. Nukman, S.S. Zakariyah, Laser Lap Joining of Dissimilar Materials - A Review of Factors Affecting Joint Strength, Mater. Manuf. Process. (2013) 130715070734009. doi:10.1080/10426914.2013.792413.

[3] M.A. Huff, A.D. Nikolich, M.A. Schmidt, Design of sealed cavity microstructures formed by silicon wafer bonding, J. Microelectromechanical Syst. 2 (1993) 7481. doi:10.1109/84.232603.

[4] D. Ando, K. Oishi, T. Nakamura, S. Umeda, Glass direct bonding technology for hermetic seal package, in: Tenth Annu. Int. Workshop Micro Electro Mech. Syst. 1997 MEMS 97 Proc. IEEE, 1997: pp. 186-190.

doi:10.1109/MEMSYS.1997.581800.

[5] M.J. Wild, A. Gillner, R. Poprawe, Locally selective bonding of silicon and glass with laser, Sens. Actuators Phys. 93 (2001) 63-69. doi:10.1016/S09244247(01)00622-7.

[6] Q. Wu, N. Lorenz, K.M. Cannon, D.P. Hand, Glass Frit as a Hermetic Joining Layer in Laser Based Joining of Miniature Devices, IEEE Trans. Compon. Packag. Technol. 33 (2010) 470-477. doi:10.1109/TCAPT.2010.2045000.

[7] J. Oberhammer, F. Niklaus, G. Stemme, Sealing of adhesive bonded devices on wafer level, Sens. Actuators Phys. 110 (2004) 407-412. doi:10.1016/j.sna.2003.06.003. 
[8] W. Watanabe, S. Onda, T. Tamaki, K. Itoh, J. Nishii, Space-selective laser joining of dissimilar transparent materials using femtosecond laser pulses, Appl. Phys. Lett. 89 (2006) 021106. doi:10.1063/1.2221393.

[9] I. Miyamoto, A. Horn, J. Gottmann, Local Melting of Glass Material and Its Application to Direct Fusion Welding by Ps-laser Pulses, J. Laser MicroNanoengineering. 2 (2007) 7-14. doi:10.2961/jmn.2007.01.0002.

[10] I. Miyamoto, K. Cvecek, Y. Okamoto, M. Schmidt, Novel fusion welding technology of glass using ultrashort pulse lasers, Phys. Procedia. 5, Part A (2010) 483-493. doi:10.1016/j.phpro.2010.08.171.

[11] A. Horn, I. Mingareev, A. Werth, M. Kachel, U. Brenk, Investigations on ultrafast welding of glass-glass and glass-silicon, Appl. Phys. A. 93 (2008) 171-175. doi:10.1007/s00339-008-4654-4.

[12] H. Huang, L.-M. Yang, J. Liu, Ultrashort pulsed fiber laser welding and sealing of transparent materials, Appl. Opt. 51 (2012) 2979-2986. doi:10.1364/AO.51.002979.

[13] J. Chen, R.M. Carter, R.R. Thomson, D.P. Hand, Avoiding the requirement for pre-existing optical contact during picosecond laser glass-to-glass welding, Opt. Express. 23 (2015) 18645. doi:10.1364/OE.23.018645.

[14] Y. Ozeki, T. Inoue, T. Tamaki, H. Yamaguchi, S. Onda, W. Watanabe, et al., Direct Welding between Copper and Glass Substrates with Femtosecond Laser Pulses, Appl. Phys. Express. 1 (2008) 082601. doi:10.1143/APEX.1.082601.

[15] R.M. Carter, J. Chen, J.D. Shephard, R.R. Thomson, D.P. Hand, Picosecond laser welding of similar and dissimilar materials, Appl. Opt. 53 (2014) 4233. doi:10.1364/AO.53.004233. 
[16] W. Liu, U. Köster, Microstructures and properties of interpenetrating alumina/aluminium composites made by reaction of $\mathrm{SiO} 2$ glass preforms with molten aluminium, Mater. Sci. Eng. A. 210 (1996) 1-7. doi:10.1016/09215093(95)10078-4.

[17] R.W. Jackson III, The Effect of Reaction and Infiltration on the Degradation of Refractory Ceramics by Molten Metals, PhD thesis, University of Pittsburgh, 2010.

[18] M. Hoseini, M. Meratian, Fabrication of in situ aluminum-alumina composite with glass powder, J. Alloys Compd. 471 (2009) 378-382. doi:10.1016/j.jallcom.2008.03.103.

[19] P. Liu, H. Cui, C.X. Wang, G.W. Yang, From nanocrystal synthesis to functional nanostructure fabrication: laser ablation in liquid, Phys. Chem. Chem. Phys. 12 (2010) 3942-3952. doi:10.1039/B918759F.

[20] I.L. Liu, P. Shen, S.Y. Chen, H+- and Al2+-Codoped Al2O3 Nanoparticles with Spinel-Type Related Structures by Pulsed Laser Ablation in Water, J. Phys. Chem. C. 114 (2010) 7751-7757. doi:10.1021/jp1002325.

[21] J. Lam, D. Amans, F. Chaput, M. Diouf, G. Ledoux, N. Mary, et al., Y-Al2O3 nanoparticles synthesised by pulsed laser ablation in liquids: a plasma analysis, Phys. Chem. Chem. Phys. 16 (2013) 963-973. doi:10.1039/C3CP53748J.

[22] Y. Farazila, Y. Miyashita, W. Hua, Y. Mutoh, Y. Otsuka, YAG Laser Spot Welding of PET and Metallic Materials, J. Laser MicroNanoengineering. 6 (2011) 69-74. doi:10.2961/jlmn.2011.01.0015.

[23] I. Barkshire, P. Karduck, W.P. Rehbach, S. Richter, High-Spatial-Resolution Low-Energy Electron Beam X-Ray Microanalysis, Microchim. Acta. 132 (2000) 113-128. doi:10.1007/s006040050052. 
[24] Y. Repelin, E. Husson, Etudes structurales d'alumines de transition. I-alumines gamma et delta, Mater. Res. Bull. 25 (1990) 611-621. doi:10.1016/00255408(90)90027-Y.

[25] F. Di Niso, C. Gaudiuso, T. Sibillano, F.P. Mezzapesa, A. Ancona, P.M. Lugarà, Role of heat accumulation on the incubation effect in multi-shot laser ablation of stainless steel at high repetition rates, Opt. Express. 22 (2014) 12200. doi:10.1364/OE.22.012200.

[26] J. König, S. Nolte, A. Tünnermann, Plasma evolution during metal ablation with ultrashort laser pulses, Opt. Express. 13 (2005) 10597. doi:10.1364/OPEX.13.010597.

[27] K. Ostrikov, E.C. Neyts, M. Meyyappan, Plasma nanoscience: from nano-solids in plasmas to nano-plasmas in solids, Adv. Phys. 62 (2013) 113-224. doi:10.1080/00018732.2013.808047.

[28] S. Katayama, Handbook of Laser Welding Technologies, Elsevier, 2013.

[29] B. Jaeggi, B. Neuenschwander, M. Schmid, M. Muralt, J. Zuercher, U. Hunziker, Influence of the Pulse Duration in the ps-Regime on the Ablation Efficiency of Metals, Phys. Procedia. 12 (2011) 164-171. doi:10.1016/j.phpro.2011.03.118.

[30] K.-H. Leitz, B. Redlingshöfer, Y. Reg, A. Otto, M. Schmidt, Metal Ablation with Short and Ultrashort Laser Pulses, Phys. Procedia. 12 (2011) 230-238. doi:10.1016/j.phpro.2011.03.128.

[31] A. Miotello, R. Kelly, Laser-induced phase explosion: new physical problems when a condensed phase approaches the thermodynamic critical temperature:, Appl. Phys. Mater. Sci. Process. 69 (1999) S67-S73.

doi:10.1007/s003399900296. 
[32] M. Straw, S. Randolph, Direct spatiotemporal analysis of femtosecond laserinduced plasma-mediated chemical reactions, Laser Phys. Lett. 11 (2014) 035601. doi:10.1088/1612-2011/11/3/035601.

[33] C.G. Levi, V. Jayaram, J.J. Valencia, R. Mehrabian, Phase selection in electrohydrodynamic atomization of alumina, J. Mater. Res. 3 (1988) 969-983. doi:10.1557/JMR.1988.0969.

[34] J.M. Guilemany, J. Nutting, M.J. Dougan, A transmission electron microscopy study of the microstructures present in alumina coatings produced by plasma spraying, J. Therm. Spray Technol. 6 (1997) 425-429. doi:10.1007/s11666997-0025-5.

[35] B. Kumar, R.K. Thareja, Synthesis of aluminum oxide nanoparticles using laser ablation in liquid, Phys. Status Solidi C. 7 (2010) 1409-1412. doi:10.1002/pssc.200983356.

[36] I. Levin, D. Brandon, Metastable Alumina Polymorphs: Crystal Structures and Transition Sequences, J. Am. Ceram. Soc. 81 (1998) 1995-2012. doi:10.1111/j.1151-2916.1998.tb02581.x.

[37] R.-S. Zhou, R.L. Snyder, Structures and transformation mechanisms of the $\eta, Y$ and $\theta$ transition aluminas, Acta Crystallogr. Sect. B. 47 (1991) 617-630. doi:10.1107/S0108768191002719.

[38] S. Ansell, S. Krishnan, J.K.R. Weber, J.J. Felten, P.C. Nordine, M.A. Beno, et al., Structure of Liquid Aluminum Oxide, Phys. Rev. Lett. 78 (1997) 464-466. doi:10.1103/PhysRevLett.78.464.

[39] J.M. McHale, A. Auroux, A.J. Perrotta, A. Navrotsky, Surface Energies and Thermodynamic Phase Stability in Nanocrystalline Aluminas, Science. 277 (1997) 788-791. doi:10.1126/science.277.5327.788. 


\section{Figure Captions}

Fig. 1 Overview of the $2.5 \mathrm{~mm}$ diameter spiral-shaped weld areas produced by stage translation, with a pitch of $100 \mathrm{~mm}$, and a travel speed of $1 \mathrm{~mm} . \mathrm{s}-1$; (a) optical micrograph of the weld, viewed through the glass sheet; (b) low magnification SEM backscattered electron image of a typical cross-section through three neighboring weld tracks, from the region indicated by the white rectangle in (a); the white arrows indicate the weld beads.

Fig. 2 Typical cross section of a single weld track showing; (a) an annotated BSE-SEM image of the main beam interaction area and surrounding features of interest, along with (b) a corresponding colour coded $\mathrm{Al}, \mathrm{Si}$, O EDS, map of the same region.

Fig. 3 SEM backscattered electron image of a typical central main weld bead cross-section and corresponding elemental distribution maps for $\mathrm{Si}, \mathrm{O}$ and $\mathrm{Al}$. The labelled arrows are referred to in the text.

Fig. 4 SEM Backscattered electron image of a weld bead cross-section prepared by Ar-ion beam polishing, showing the sub-surface grain structure in the Al plate near the weld region.

Fig. 5 SEM-EDS line scan across the central weld region.

Fig. 6 STEM-HAADF image from (a) of a longitudinal section of the weld bead and (b) and (c) a Si and $\mathrm{Al}$ composite and $\mathrm{O}$ elemental distribution maps, respectively, from the white dotted rectangular area indicated in (a).

Fig. 7 TEM bright field images of the micro-porous, nano-crystalline, Si-rich region in the central area of the weld at; (a) low and (b) high magnification. The SAD insert in (b) is from the small area indicated by the dashed circle in (a). 
Fig. 8 TEM images from a region close to the Al substrate side (box (i) in Fig. 6(a)), revealing an Al-oxide rich area fragmented by fine, evenly-spaced parallel cracks; the area marked by the dashed circle produced the SADP in (b), is indexed as $\delta$ $\mathrm{Al}_{2} \mathrm{O}_{3}$. Composite STEM-EDS maps of the $\mathrm{Al}$ and $\mathrm{Si}$ and an $\mathrm{O}$ distributions for the same region are provided in (c) and (d), respectively.

Fig. 9 Fine, submicron, aluminium oxide particles, indexed as $\delta-\mathrm{Al}_{2} \mathrm{O}_{3}$, close to the glass interface (region marked by box (ii) in Fig. 6(a)): (a) TEM image of the interface region with an SAD pattern from the dark particle at centre-left area, shown in the inset; composite $\mathrm{Al} \& \mathrm{Si}$ and $\mathrm{O}$ distribution maps for the area marked in (a) are shown in (b) and (c), respectively.

Fig. 10 Interface reaction layer formed in the vicinity of the laser interaction volume analysed by STEM (dashed line in (a) marks location of FIB lamella extraction): (b) an ADF image of the region shows the fragmented reaction layer; the lower left inset shows a diffraction pattern acquired from the circled area indicating a mostlyamorphous structure; composite $\mathrm{Al} \& \mathrm{Si}$ and $\mathrm{O}$ distribution maps for the rectangular area in (b) are shown in (c) and (d), respectively.

Fig. 11 TEM image of the fine fragments present within the interface reaction layer. A CBED pattern, produced by the dark fragment marked by the arrow and indexed as $\gamma$-phase $\mathrm{Al}_{2} \mathrm{O}_{3}$, is shown as an inset. 

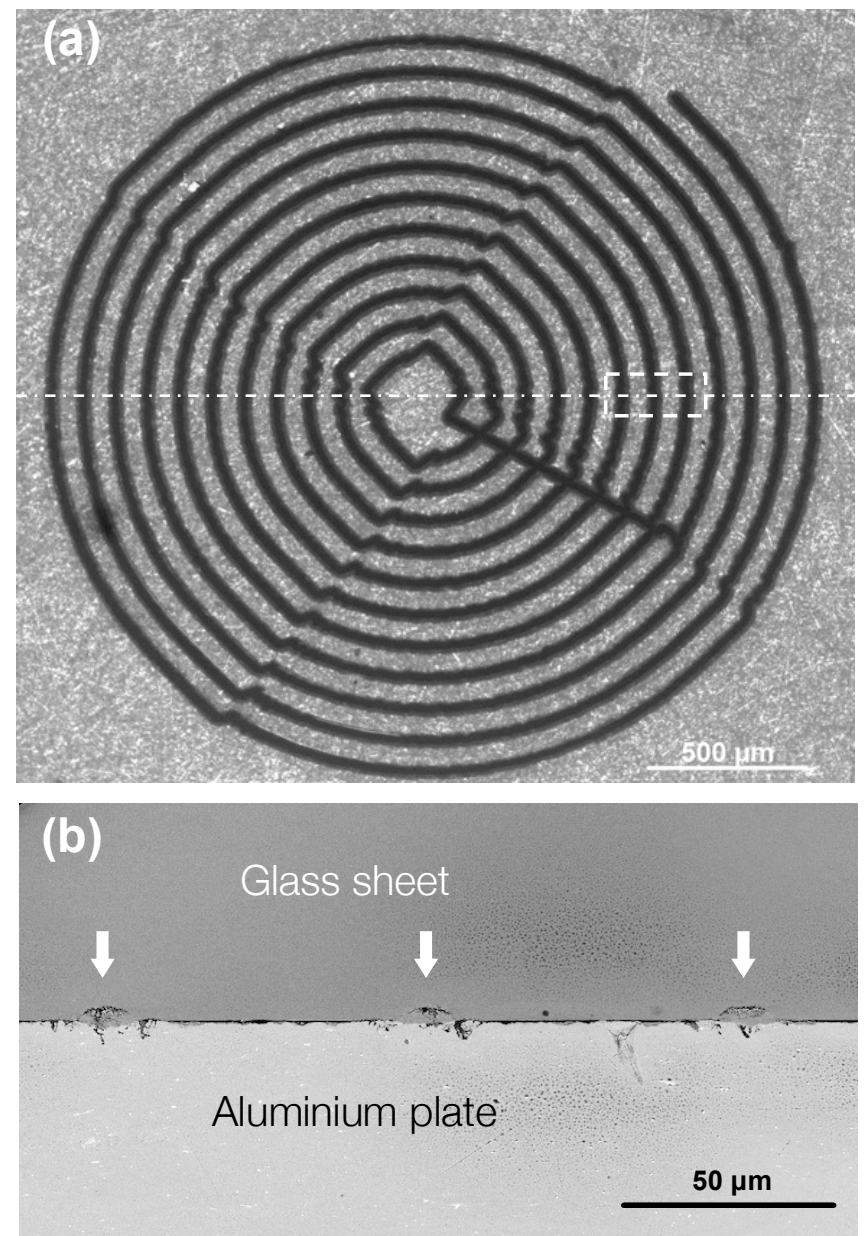

Fig. 1 Overview of the $2.5 \mathrm{~mm}$ diameter spiral-shaped weld areas produced by stage translation, with a pitch of $100 \mu \mathrm{m}$, and a travel speed of $1 \mathrm{~mm} . \mathrm{s}^{-1}$; (a) optical micrograph of the weld, viewed through the glass sheet; (b) low magnification SEM backscattered electron image of a typical cross-section through three neighboring weld tracks, from the region indicated by the white rectangle in (a); the white arrows indicate the weld beads. 

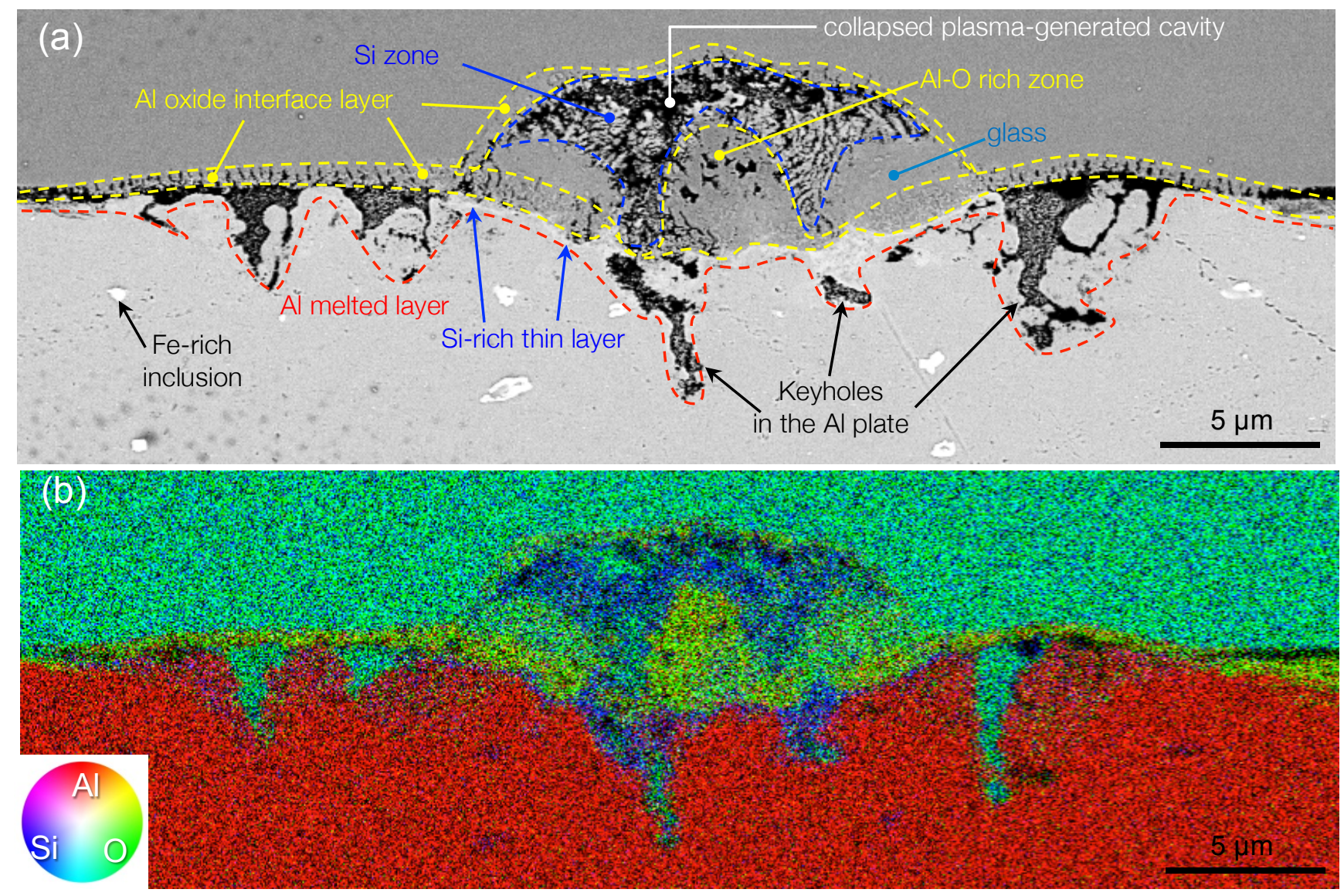

Fig. 2 Typical cross section of a single weld track showing; (a) an annotated BSESEM image of the main beam interaction area and surrounding features of interest, along with (b) a corresponding colour coded $\mathrm{Al}$, Si, O EDS, map of the same region. 


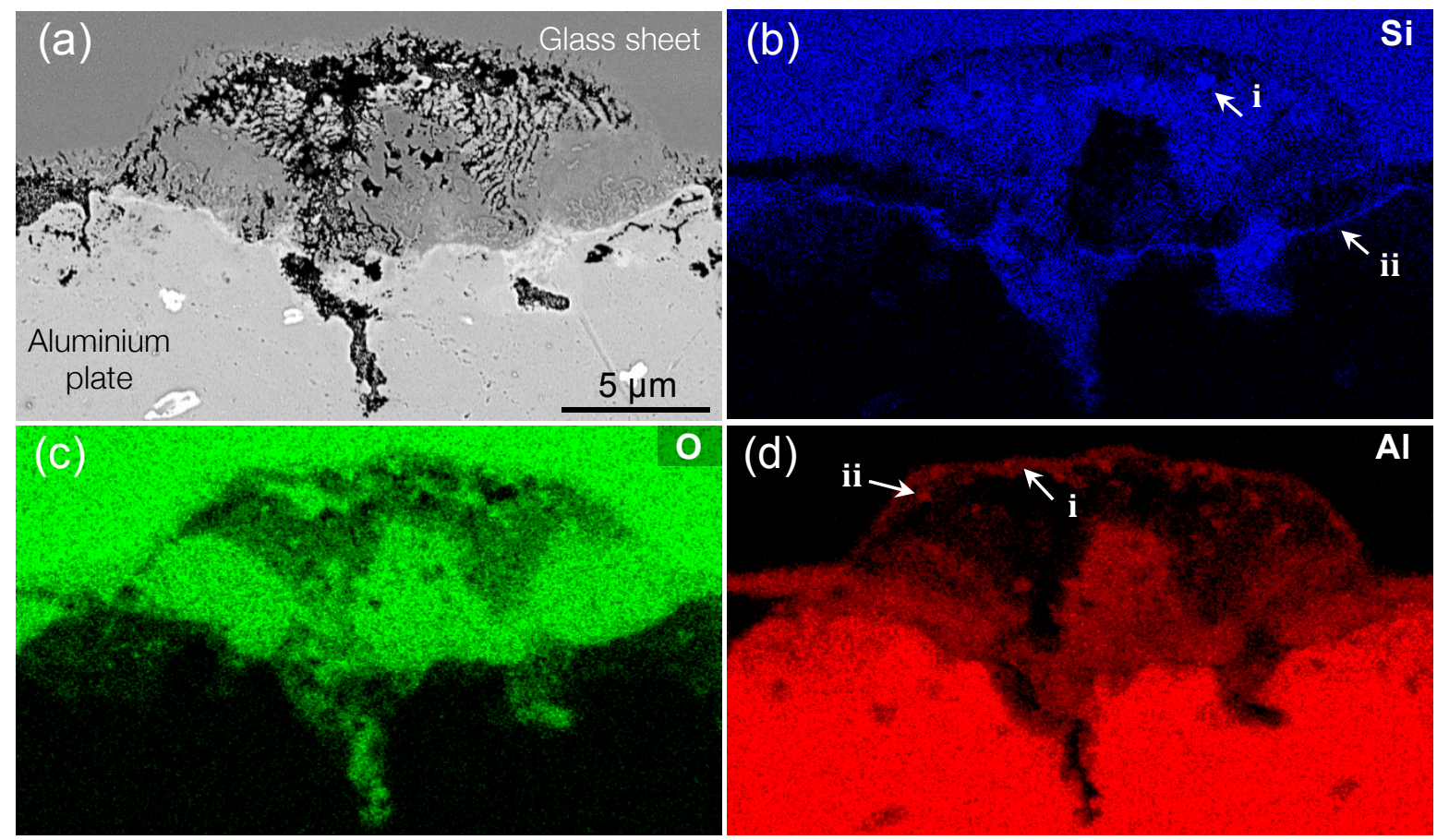

Fig. 3 SEM backscattered electron image of a typical central main weld bead crosssection and corresponding elemental distribution maps for $\mathrm{Si}, \mathrm{O}$ and $\mathrm{Al}$. The labelled arrows are referred to in the text. 


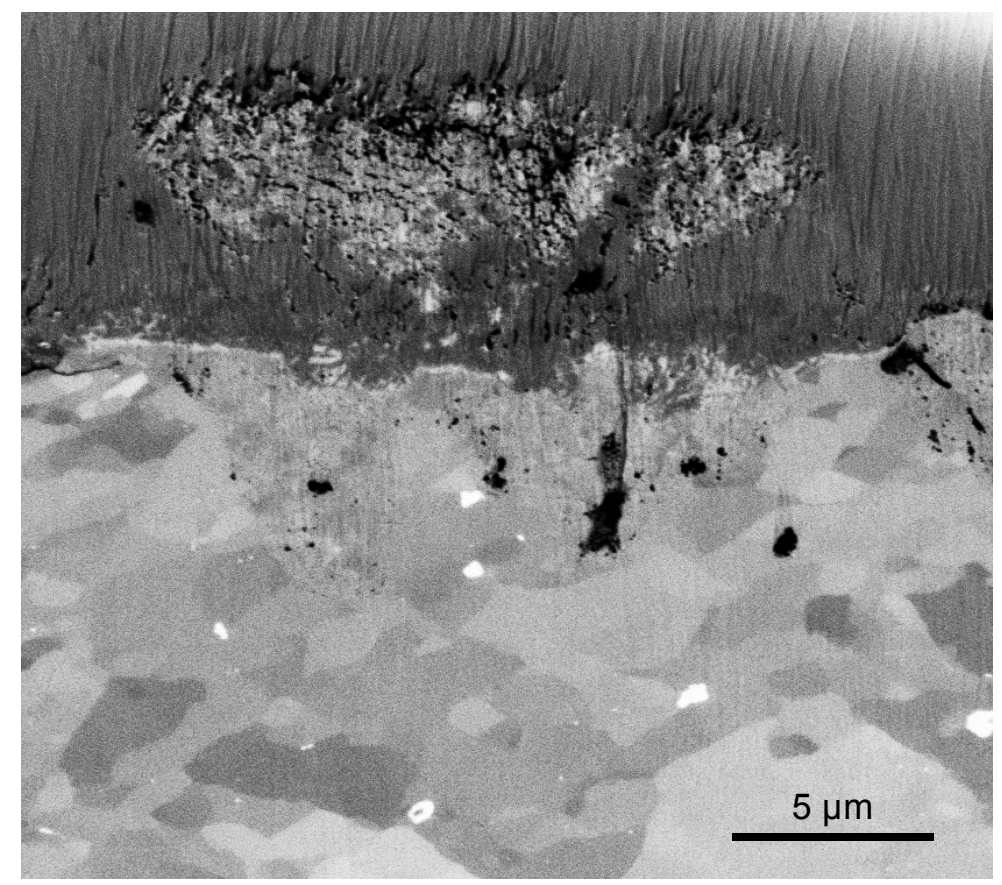

Fig. 4 SEM backscattered electron image of a weld bead crosssection prepared by Ar-ion beam polishing, showing the subsurface grain structure in the Al plate near the weld region. 


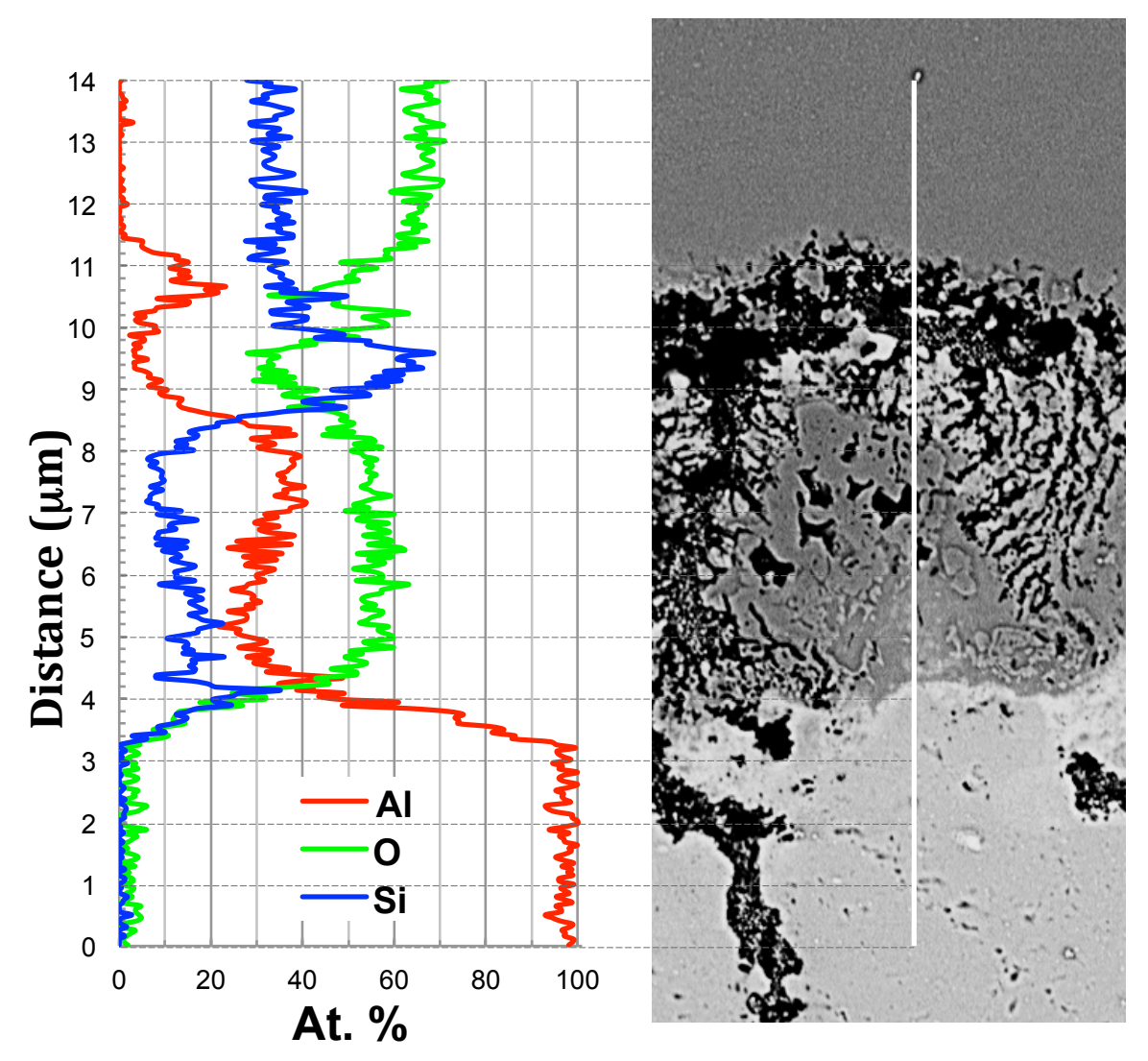

Fig. 5 SEM-EDS line scan across the central weld region. 


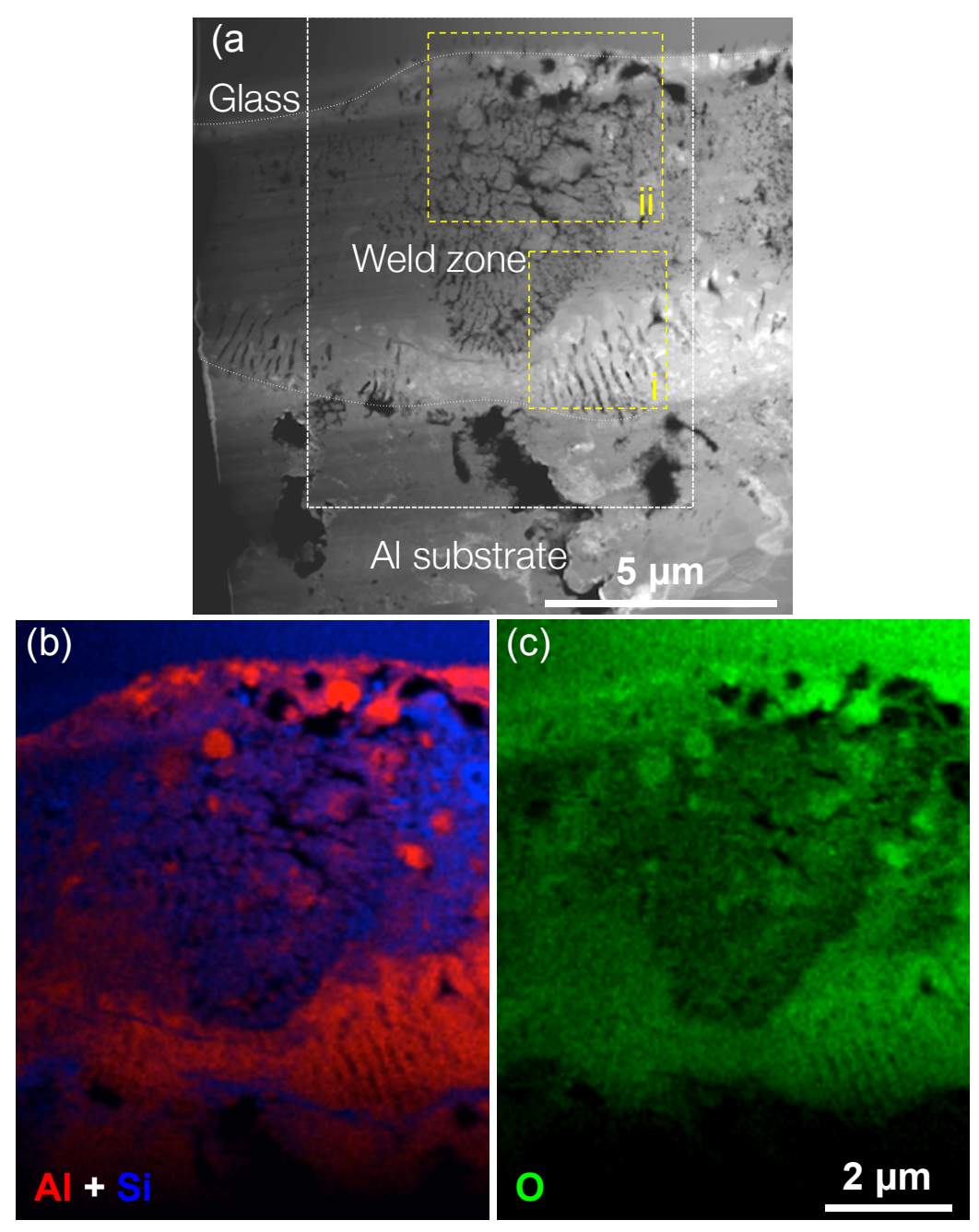

Fig. 6 STEM-HAADF image from (a) of a longitudinal section of the weld bead and (b) and (c) a Si and Al composite and O elemental distribution maps, respectively, from the white dotted rectangular area indicated in (a). 


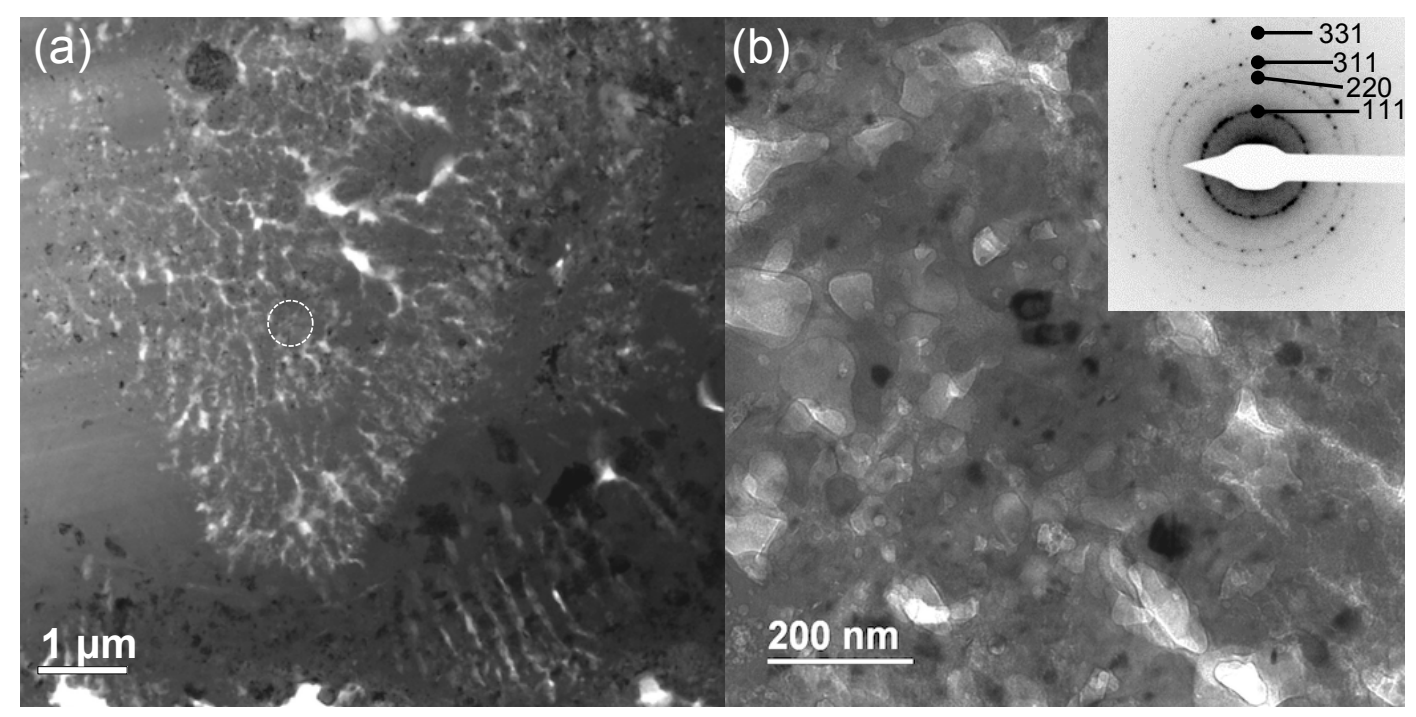

Fig. 7 TEM bright field images of the micro-porous, nano-crystalline, Si-rich region in the central area of the weld at; (a) low and (b) high magnification. The SAD insert in (b) is from the small area indicated by the dashed circle in (a). 


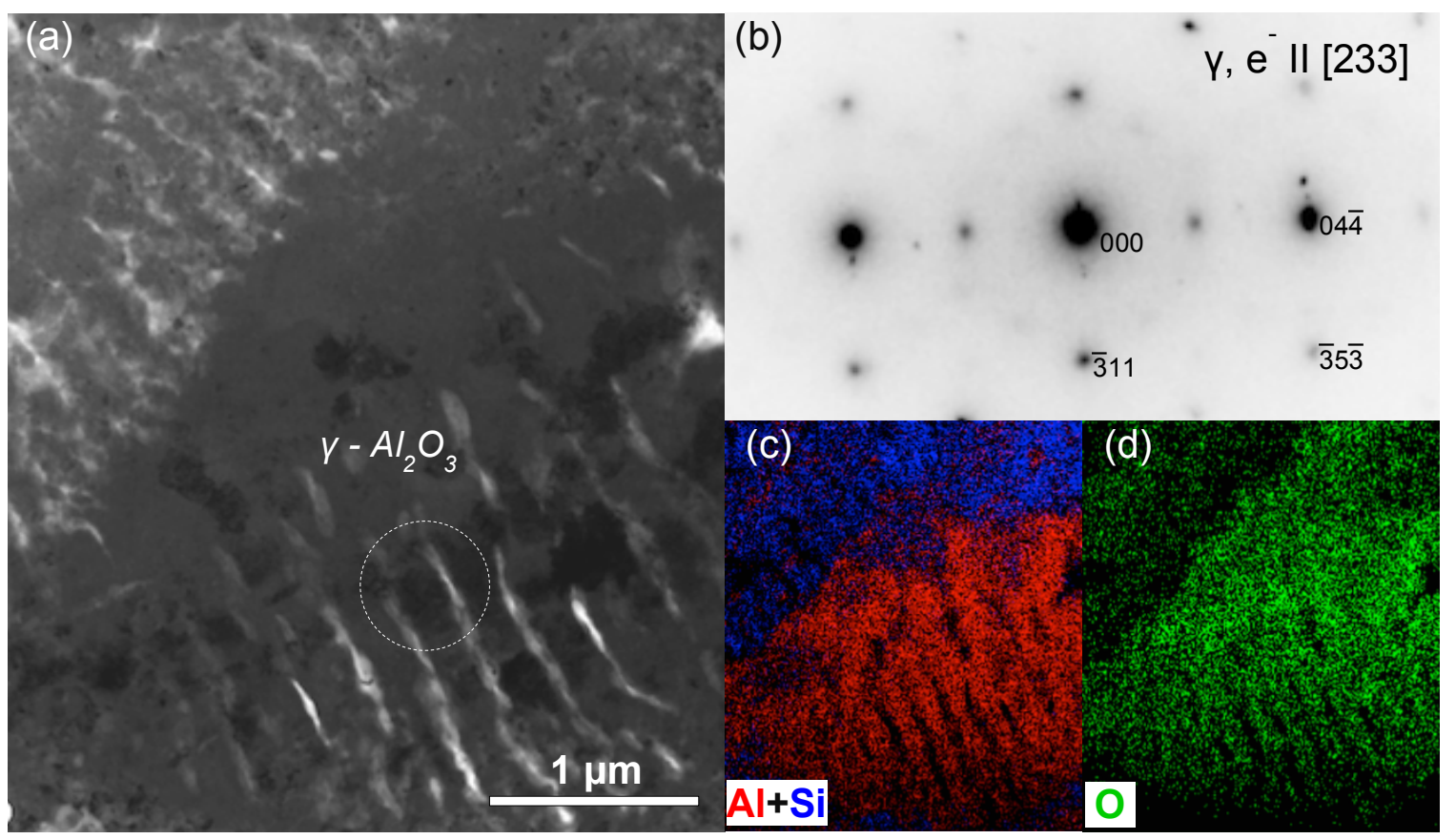

Fig. 8 TEM images from a region close to the Al substrate side (box (i) in Fig. 6(a)), revealing an $\mathrm{Al}$-oxide rich area fragmented by fine, evenly-spaced parallel cracks; the area marked by the dashed circle produced the SADP in (b), is indexed as $\gamma-\mathrm{Al}_{2} \mathrm{O}_{3}$. Composite STEM-EDS maps of the $\mathrm{Al}$ and $\mathrm{Si}$ and an $\mathrm{O}$ distributions for the same region are provided in (c) and (d), respectively. 


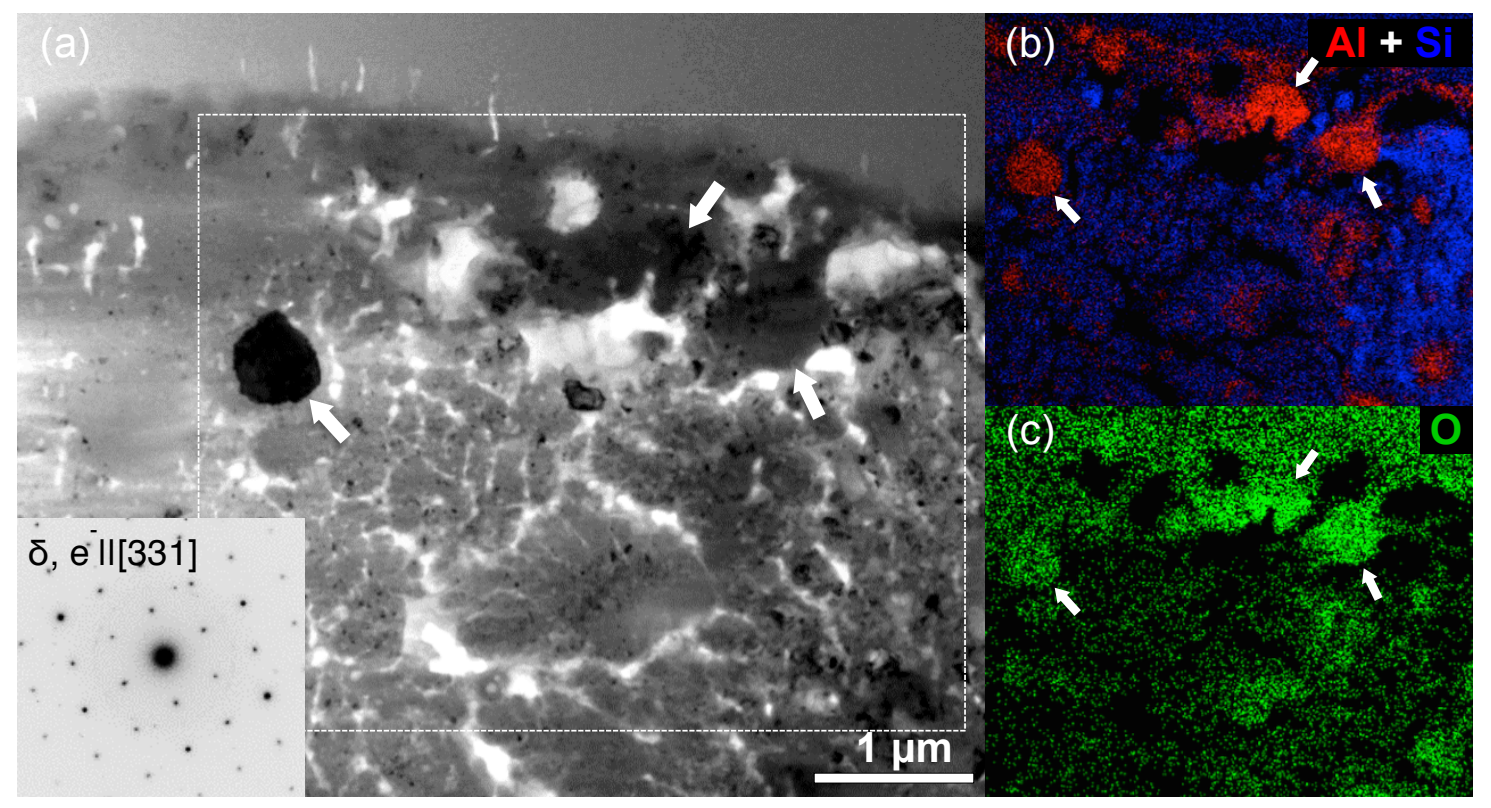

Fig. 9 Fine, submicron, aluminum oxide particles, indexed as $\delta-\mathrm{Al}_{2} \mathrm{O}_{3}$, close to the glass interface (region marked by box (ii) in Fig. 6(a)): (a) TEM image of the interface region with an SAD pattern from the dark particle at centre-left area, shown in the inset; composite Al \& Si and O distribution maps for the area marked in (a) are shown in (b) and (c), respectively. 

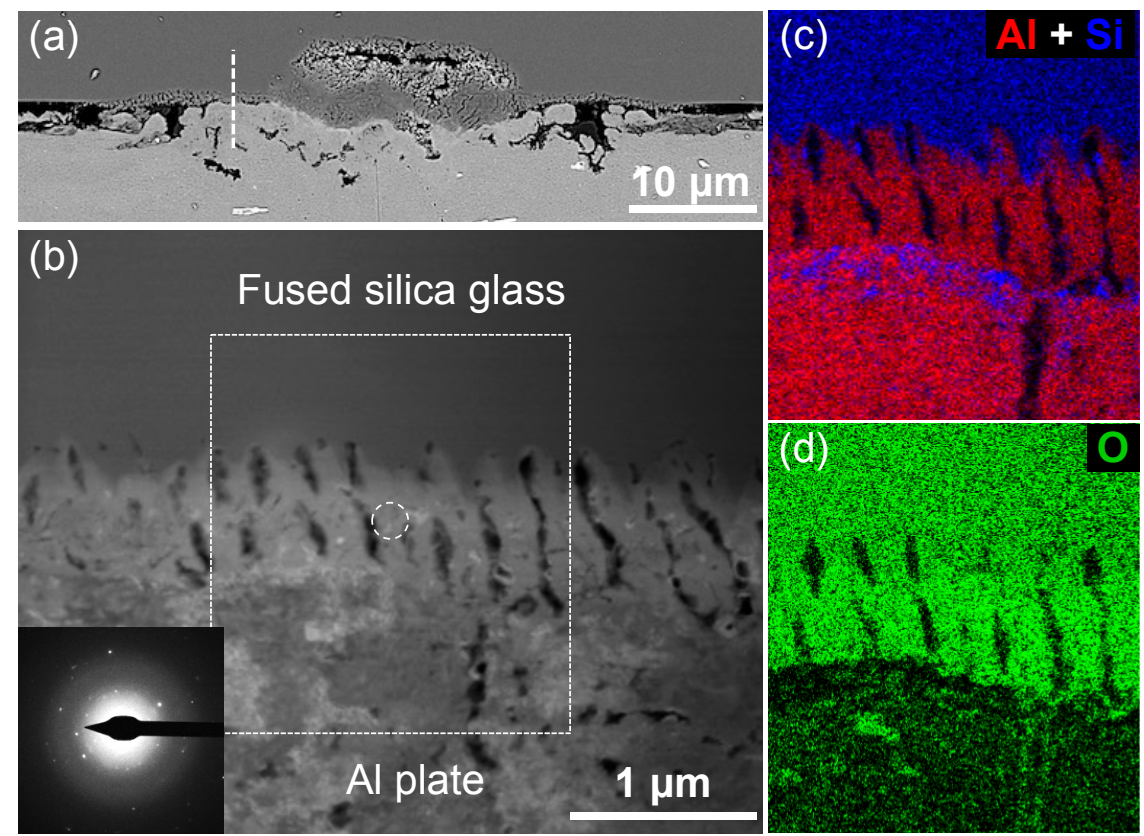

Fig. 10 Interface reaction layer formed in the vicinity of the laser interaction volume analysed by STEM (dashed line in (a) marks location of FIB lamella extraction): (b) an ADF image of the region shows the fragmented reaction layer; the lower left inset shows a diffraction pattern acquired from the circled area indicating a mostlyamorphous structure; composite $\mathrm{Al} \& \mathrm{Si}$ and $\mathrm{O}$ distribution maps for the rectangular area in (b) are shown in (c) and (d), respectively. 


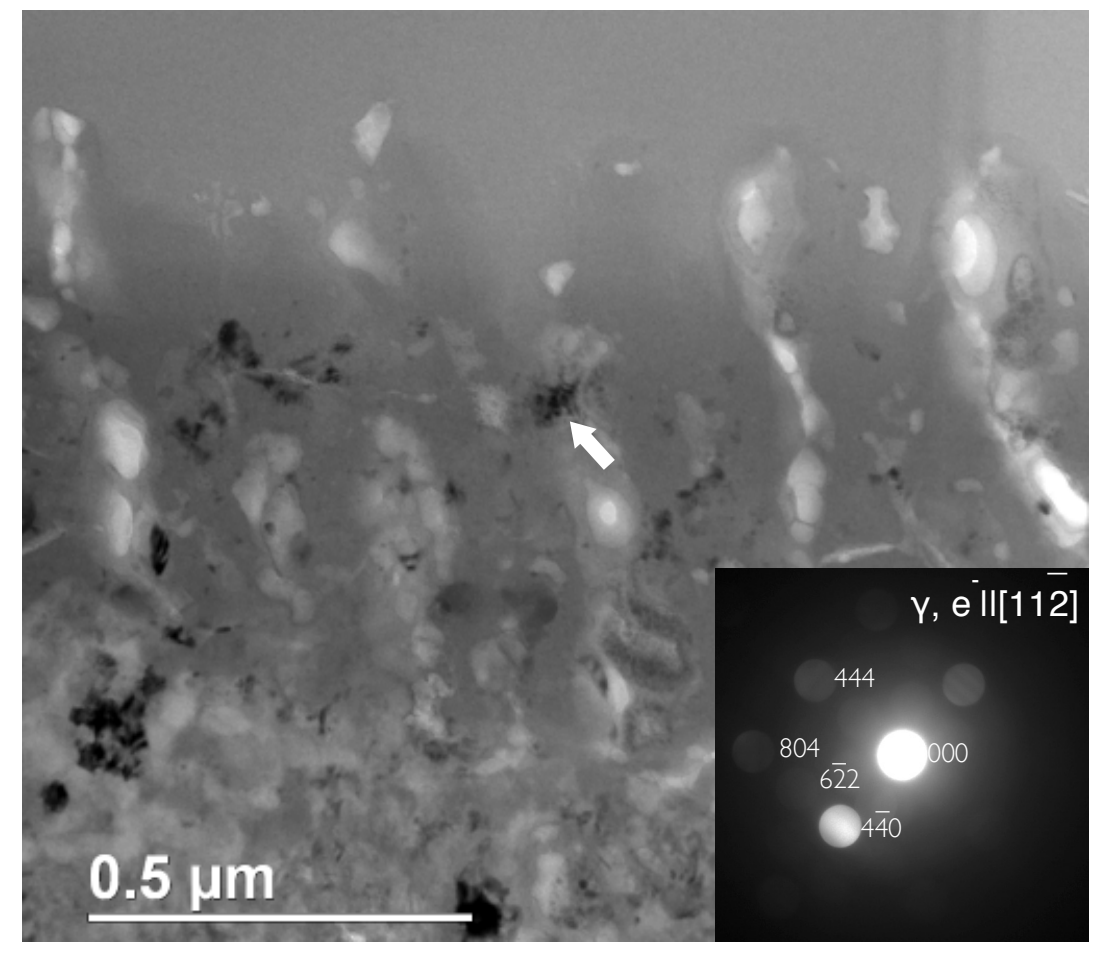

Fig. 11 TEM image of the fine fragments present within the interface reaction layer. A CBED pattern, produced by the dark fragment marked by the arrow and indexed as $\gamma$-phase $\mathrm{Al}_{2} \mathrm{O}_{3}$, is shown as an inset. 